Egyptian

Orthodontic Journal

\title{
DENTO-FACIAL EFFECTS AFTER THE USE OF BONE ANCHORAGE PENDULUM APPLIANCE
}

\author{
Safaa M. Gaballa ${ }^{1}$,Eman M. Elshorbagy ${ }^{2}$, \\ Safaa A. Ghobashy ${ }^{3}$, Mohamed Ellithy ${ }^{4}$
}

\section{ABSTRACT:}

This study was conducted to evaluate the dentofacial changes after distalization of maxillary first molars using the bone anchorage pendulum appliance (BAPA) and the conventional pendulum appliance (PA) in the treatment of dental Class II.

Thirty patients were selected from the clinic of Orthodontic Department, Faculty of Dentistry, Tanta University, seeking orthodontic treatment. Their ages were ranged from 13-16 years for both sexes. The patients were divided into two equal groups. The first group consisted of 15 patients treated with Hilgers pendulum appliances (PA). The second group consisted of 15 patients were treated with bone anchorage pendulum appliances (BAPA). The skeletal and dental changes were measured on lateral cephalometric $x$-ray films and dental casts obtained before and after the distalization. $\tau$ - test was used for statistical evaluation.

In both groups all first maxillary molars were moved distally into a super class I relationship successfully in 6.49 months for BAPA group and 5.65 months for $P \mathcal{A}$ group, The average amounts of molar distal movement and tipping were $\left(5.12 \mathrm{~mm}, 7.6^{\circ}\right)$ in the BAPA group and $\left(6.19 \mathrm{~mm}, 8.8^{\circ}\right)$ in the $\mathcal{P A}$ group. The result showed that, the molar tipped $1.48^{\circ}$ per millimeter of distal tooth

1- Professor of orthodontics, Faculty of Dentistry, Tanta University.

2- Professor of orthodontics, Faculty of Dentistry, Tanta University.

3- Associate professor of orthodontics, Faculty of Dentistry, Tanta University.

4- Master degree of orthodontics, Faculty of Dentistry, Tanta University. 
Egyptian

Orthodontic Journal

movement in $\mathscr{B A} \mathcal{A} \mathcal{A}$ group, and $1.42^{\circ}$ per millimeter in $\mathscr{P A}$ group. The maxillary second premolars, first premolars and central incisors in BAPA group exhibited significant distal movement which would positively affect the prognosis in contrast there was a significant mesial tipping of the maxillary first premolars and central incisors in $\mathscr{P A}$ group. Regarding anterior anchorage, there was a reciprocal anchorage loss in the form of maxillary incisors protrusion in $P \mathcal{A}$ group; however $B \mathcal{A} \mathcal{A}$ A group showed no anchorage Coss. Lower anterior and total anterior Facial heights increased significantly during the treatment in the two groups. The maxillary intermolar widths were significantly increased in both groups. The maxillary arch perimeter was increased in both groups, which was more pronounced in $P$ A group indicating anchorage Loss.

The results showed that the BAPA appliance is an effective and minimally invasive, compliance free alternative for intraoral molar distalization without anchorage loss.

\section{INTRODUCTION}

Class II malocclusion is the most frequent treatment problem in the orthodontic practice, and the major objectives of its treatment are to establish a stable Class I molar and canine relationship in harmony with other facial features and to relieve crowding if present ${ }^{(1,2)}$

The distalization mechanics to correct Class II malocclusions is a common treatment modality typically used in patients with maxillary skeletal or dentoalveolar protrusion or both. Molar distalization can be used when extraction of maxillary teeth is not indicated and the mandibular tooth-size/arch-perimeter relationship does not permit mesial movement of the lower molars ${ }^{(3)}$.

Runge et $\mathrm{al}^{(4)}$ mentioned that the intraoral distalizers were classified according to the source of anchorage into intermaxillary and intramaxillary appliances: Intermaxillary molar distalizers as Herbest appliance ${ }^{(5)}$, Jasper Jumper appliance ${ }^{(6)}$, Superspring II appliance ${ }^{(7)}$ Wilson arch appliance ${ }^{(8)}$, 
and Twin force appliance ${ }^{(9)}$. Intramaxillary molar distalizers as Repelling magnets $^{(10)}$, Jones Jig appliance ${ }^{(11)}$, Pendulum appliance ${ }^{(12)}$, Nickel titanium (NiTi) coil spring ${ }^{(13)}$, Fixed Piston appliance ${ }^{(14)}$, Distal- Jet appliance ${ }^{(15)}$, Modified Nance appliance ${ }^{(16)}$ and other appliances ${ }^{(17-22)}$.

Previous authors reported that a molar distalization appliance should meet the following criteria: acceptable esthetics, comfort, minimal need for patient compliance, minimal loss of anterior anchorage, bodily movement of molars to avoid undesirable side effects, and minimal chair side time for placement and reactivation. The Hilgers claimed that the pendulum appliance satisfies most of these requirements ${ }^{(23,24)}$. Hilgers $^{(12)}$ found that patient tolerance of the pendulum appliance had been excellent as they adapted to the appliance within a week without tongue irritation and difficulty in swallowing. Class II correction as well as expansion and improvement of arch form, can be achieved with little or no need for patient compliance. However, forward movements of anchoring teeth and unwanted tipping of the maxillary molar during distalization have been the most important disadvantages of all intraoral distalizing appliances including the pendulum appliance ${ }^{(25)}$. In addition, there is a rebound tendency immediately after removal of the appliance ${ }^{(26-28)}$.

The solution to these problems had been provided by recent improvements in implant dentistry. Endosseous implants were first used as bone anchors for orthodontic appliances ${ }^{(29-33)}$ and later, onplants and intraosseous screws ${ }^{(34)}$.

Screws can be used as a direct anchorage unit that is connected to the teeth to be moved ${ }^{(35)}$, or the anchorage teeth can be stabilized with the screw that acts as an indirect anchorage unit ${ }^{(36)}$.

With the use of screws ${ }^{(37)}$, implants ${ }^{(40)}$, and miniplates ${ }^{(41)}$ as anchorage, the distal movement of the anterior teeth or posterior teeth or both without anchorage loss has become possible. Researchers attempted to counteract the large amount of tipping found in the previous studies, by modifying PA to distalize the molar with a better preservation of anterior anchorage $^{(33,37-39)}$. Byloff et $\mathrm{al}^{(36)}$ and Karcher et al ${ }^{(39)}$ used an implant 
supported pendulum appliance to obtain anchorage from an intraosseous screw instead of the premolars. The BAPA was found to be an effective intraoral distalization appliance for achieving both molar and premolar distalization without any anchorage loss.

The palatal screw implants have the advantages of easy placement and removal, with minimal anatomical limitations because of their small size and low $\operatorname{cost}^{(42,43)}$. Therefore, their clinical applications have been expanded, and they have been adopted for distalization of the maxillary molars. Very few studies were found to be dealing with bone anchorage pendulum appliance and its effectiveness in molar distalization and the movement of teeth anterior to maxillary first molars.

The aim of this study was therefore to evaluate the dentofacial changes achieved after molar distalization with BAPA and compare the results with those of similar group of patient treated with PA.

\section{SUBJECTS AND METHODS}

The sample of this study comprised 30 patients (13-16 years old) seeking orthodontic treatment in Orthodontic Department, Faculty of Dentistry, Tanta University. The patients were selected according to the following criteria:

1. Good oral hygiene.

2. None of the patients had received any orthodontic treatment.

3. Permanent dentition (patients with retained deciduous teeth will be excluded).

4. Class I skeletal relationship with an acceptable soft tissue facial profile.

5. Class II molar relationship with normal or hypodivergent growth pattern.

6. Minimal or no crowding in the mandibular arch.

7. Nonextraction treatment plan with molar distalization.

8. No tempromandibular joint disorder. 
Informed consents were obtained before treatment after explaining the treatment procedure in detail to all patients and parents. The patients were divided into two groups:

Group 1: Consisted of 15 patients were treated with PA.

Group 2: Consisted of 15 patients were treated with BAPA.

The following records were taken after thorough clinical examination:

- Extra oral and intraoral photographs before and after molar distalization.

- Panoramic x- ray film.

- Lateral cephalometric radiographs before and after molar distalization in both groups and after insertion of the titanium screw (in group 2).

- Study models before and after molar distalization.

\section{Construction of pendulum appliance, according to Hilgers ${ }^{(12)}$ (Fig1):}

- After upper first permanent molars and first premolars separation, the readymade bands were selected .For the first permanent right and left molar bands two 0.036" lingual sheaths were welded, and the four bands were fitted in their accurate position on the teeth. An accurate upper alginate impression ${ }^{*}$ was taken, and the bands were accurately positioned in the impression and secured in place with wax. The impression was poured in dental plaster stone ${ }^{* *}$.

- On the working cast 0.028" stainless-steel wire was adapted and soldered to the lingual surfaces of the premolar bands. The pendulum springs were made of 0.032 "Titanium Molybdenum Alloy wire. Two auxiliary wires were shaped and soldered to the bands of the first premolars. The acrylic button extended away from the closed helix loops of the right and left pendulum spring was fabricated.The PA was then finished and polished.

- The pendulum springs were activated extraorally on the model by bending the springs a $90^{\circ}$. About one third of the bend was lost after

\footnotetext{
* Hydrogum, Zhermack, Rovigo- Italy.

** Elite model, Zhermack, Rovigo- Italy.
} 
the insertion, resulting in $60^{\circ}$ activation, or 300 grams of distalizing force by using pressure gauge .

- The maxillary first molar bands with lingual sheaths were cemented with glass ionomer cement ${ }^{*}$. The premolar bands which incorporate the acrylic Nance button were then cemented with glass ionomer cement and were accurately fitted on the first premolars.

- The pendulum springs were inserted in the lingual sheaths on the right and left sides.

\section{Construction of Bone anchorage pendulum appliances (Fig 2):}

○ PA constructed according to Hilgers ${ }^{(12)}$, excluding the auxiliary wires that extend to the bands of the first premolars.

- Two titanium intraosseous screws ${ }^{* *}(2.0 \mathrm{~mm}$ diameter and $9 \mathrm{~mm}$ length) were used as rigid bone anchors.

○ Upper first permanent molars were separated and banded after welding of 0.036 "lingual sheaths on the lingual surfaces of the bands.

- The surgery was performed with the patient under local anesthesia.

- All screws were placed by oral surgeon in the anterior paramedian region of the median palatal suture, $7-8 \mathrm{~mm}$ posterior to the incisive foramen and 3-4 $\mathrm{mm}$ on both sides of the median line.

○ After surgery a mouthwash was prescribed for daily use and patients were instructed to clean the screws with a soft brush.

- After soft tissue healing, impressions and stone casts were obtained with the screws and upper molar bands in place. On the stone model, the screws head were blocked out with wax and pendulum springs were performed. Separating medium was placed on the model then Nance button was formed.

o The maxillary first molar bands with lingual sheaths were cemented with glass ionomer cement ${ }^{*}$.

* Medicem; Promedica, Neumunster/Germany.

** IMF intermaxillary fixation screw, Stryker, Leibinger, Germany.

* Medicem; Promedica, Neumunster/Germany. 


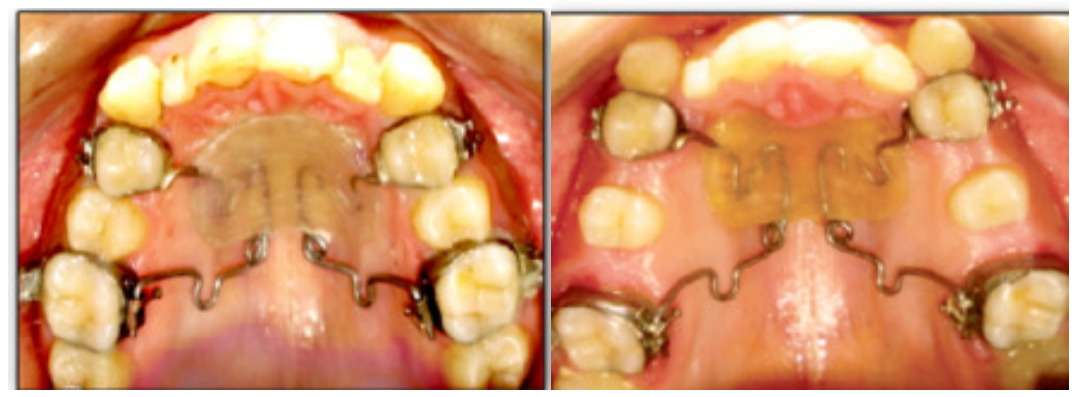

Fig (1) A case before and after distalization with PA.

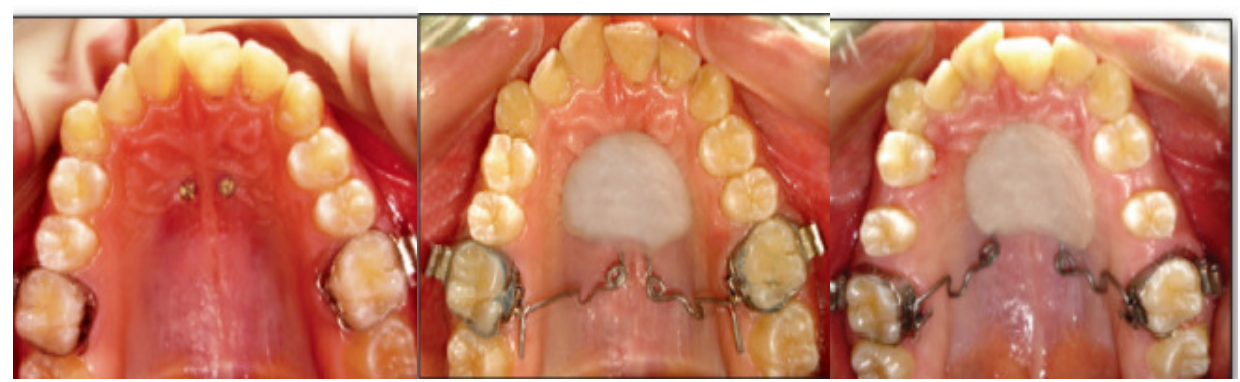

Fig (2) A case before and after distalization with BAPA appliance.

○ The Nance button with the activated pendulum springs were checked for adaptation on the palatal screws, then the acrylic plate was connected to the screw head using chemical curing composite resin ${ }^{* *}$.

- The activated pendulum springs were inserted in the lingual sheaths.

○ Patients were specially educated to maintain their oral hygiene and were asked to use a mouthwash regularly.

\section{Reactivation and Follow up:}

The patients were seen every three weeks for intraoral reactivation if needed, and to check the improvement in the position of the mesiobuccal cusp of the maxillary first permanent molars and any changes in the anchorage unit. The springs were removed from the sheaths with Weingart plier and the helix was grasped and the springs were then

${ }^{* *}$ Composite, Dental Technologies, Lincolnwood, Illinois, 60712 USA. 
opened in a distal direction to approximately $90^{\circ}$ with finger pressure. The arms were reinserted in the sheaths with Weingart plier.

After distalization (super class I molar relation), the terminal ends of the springs were deactivated to allow a passive fit in the lingual sheaths.

The corrected molar relation was maintained using a modified Nance appliance. This appliance was fabricated and cemented at the same day the distalizing appliance was removed.

\section{Dental cast analysis, Fig (3,4):(Hansen and Pancherz) ${ }^{(44)}$ :}

The maxillary and mandibular casts were mounted on simple hinge articulator utilizing wax bite taken in the centric occlusion. Then the following measurements were made on the upper arch cast using Boly gauge $^{*}$ graduated to the nearest $0.1 \mathrm{~mm}$ :

\section{1-Arch perimeter}

The maxillary arch perimeters were measured sectionally (Adkins et al) ${ }^{(45)}$ :

a- The distance from the mesial contact point of the left first permanent molar to the mesial contact point of the left first premolar.

b- The distance from the mesial contact point of the left first premolar to the mesial contact point of the left lateral incisor.

c- The distance from the mesial contact point of the left lateral incisor to the mesial contact point of the right lateral incisor.

d- The distance from the mesial contact point of the right lateral incisor to the mesial contact point of the right first premolar.

e- The distance from the mesial contact point of the right first premolar to the mesial contact point of the right first permanent molar.

Arch perimeter was calculated as the sum of $a+b+c+d+e$.

2- Maxillary inter-canine width: The maxillary inter-canine width was measured as the distance between the canine cusp tips.

\footnotetext{
* Beerrendonk 042-750 Dentaurum.
} 
3-Maxillary intermolar width: The maxillary intermolar width was measured as the distance between the mesiobuccal cusp tips of the first permanent molars.

4-Overjet: The distance from the lingual incisal edge of the most protruded maxillary incisor to the labial of the opposing mandibular central incisor tooth.

5-Overbite: The vertical overlap of the lower incisors by the upper incisors measured in percentage to the labial surfaces of the lower incisors.

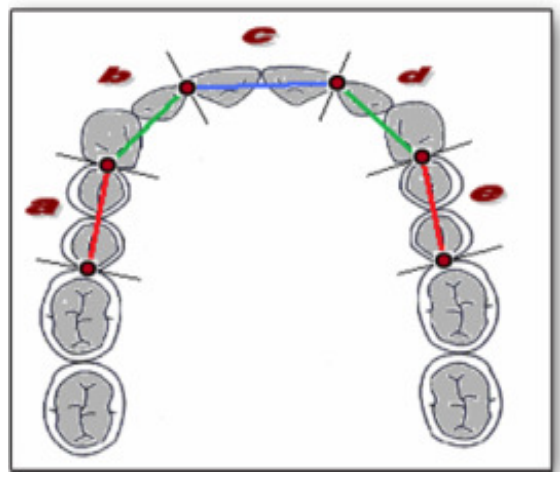

Fig(3) Arch perimeter
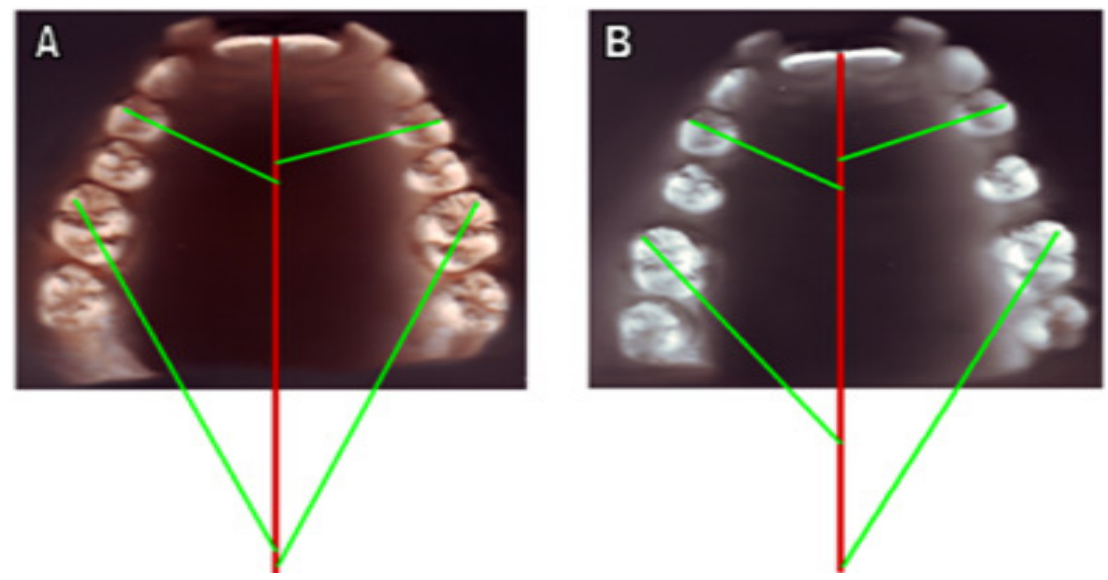

Fig (4) Model occlusal photocopies before (A) and after (B) distalization 
In order to determine the rotations of the maxillary first molars and anchorage loss of the maxillary first premolars, model photocopies were obtained as described by Champagne ${ }^{(46)}$. The median palatal suture of the study models was defined by tracing with a $0.5 \mathrm{~mm}$ pointed drawing pencil.

To evaluate the location of the first molars before and after the treatment (Fig 4), the cusp tips of these teeth were marked and the following measurements were analyzed on the model occlusal photocopies (Keles and Sayınsu) ${ }^{(20)}$.

- UL6 axis angle: Angle formed between the midline and a line passing through the mesiobuccal cusp tip and the distopalatal cusp tip of the upper left first molar.

- UR6 axis angle: Angle formed between the midline and a line passing through the mesiobuccal cusp tip and the distopalatal cusp tip of the upper right first molar.

- UL4 axis angle: Angle formed between the midline and a line passing through the buccal cusp tip and the palatal cusp tip of the upper left first premolar.

- UR4 axis angle: Angle formed between the midline and a line passing through the buccal cusp tip and the palatal cusp tip of the upper right first premolar.

\section{Lateral cephalometric $x$-ray analysis:}

Standard lateral cephalometric radiographs were recorded with the patient's closed-mouth before and after distalization. Each cephalogram was traced and analyzed by the same operator and checked by the supervisors.

The radiographs were remeasured after a period of 2 weeks, and the readings of the first estimation were compared to the second one. A tolerance limit of $0.5 \mathrm{~mm}$ and $0.5^{\circ}$ was established for the difference between the first and second observations of angular and linear measurements. If the limit was exceeded, a new tracing and measurements were made.

- Cephalometric reference points, lines, and planes. According to

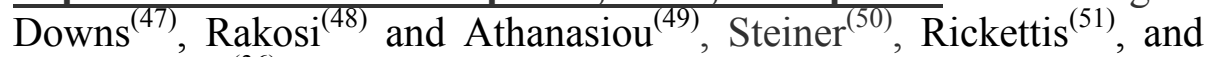
Kircelli et al. ${ }^{(36)}$ : 
- Skeletal measurements (Fig5). According to Steiner ${ }^{(50)}, \mathrm{McNamar}^{(52)}$, and Jacobson ${ }^{(53}$

1- SNA angle: the angle formed by the intersection of SN and NA.

2- SNB angle: the angle formed by the intersection of SN and NB.

3- ANB angle: the angle formed by the intersection of NA and NB.

4- FMA angle: the angle formed by the intersection of mandibular plane and Frankfort horizontal plane.

5- Total anterior facial height (N-Me): The distance in $\mathrm{mm}$ between $\mathrm{N}$ and Me.

6- Lower anterior facial height (ANS-Me): The distance in $\mathrm{mm}$ between ANS and Me.

7- Posterior facial height (S-Go): The distance in $\mathrm{mm}$ between $\mathrm{S}$ and Go.

\section{- Dental linear measurements Fig(6):}

The pterygoid vertical plane and the Frankfort horizontal plane were used as reference planes for measuring the cephalometric dental changes ${ }^{(36)}$.

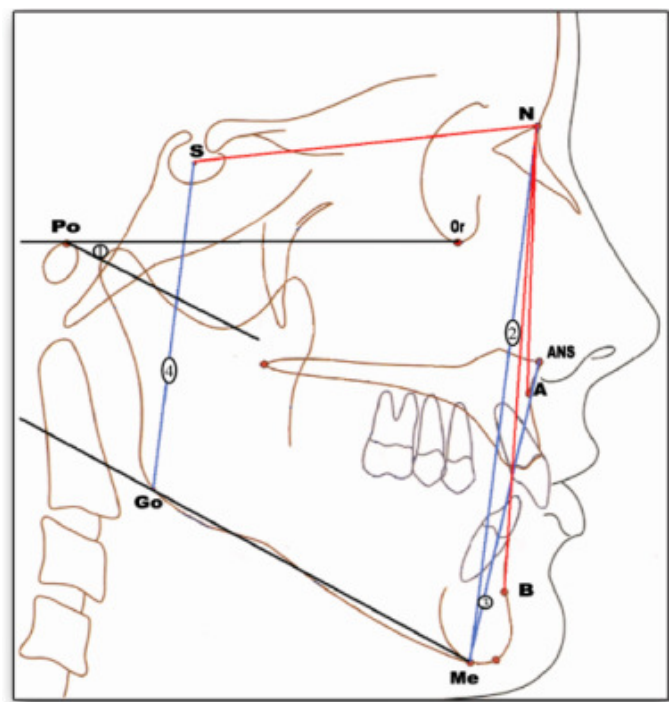

Fig (5) Skeletal measurements; Angular: SNA, ANB, ANB.1: FMP, and linear; 2: N-Me 3:ANS-Me, 4: S-Go. 


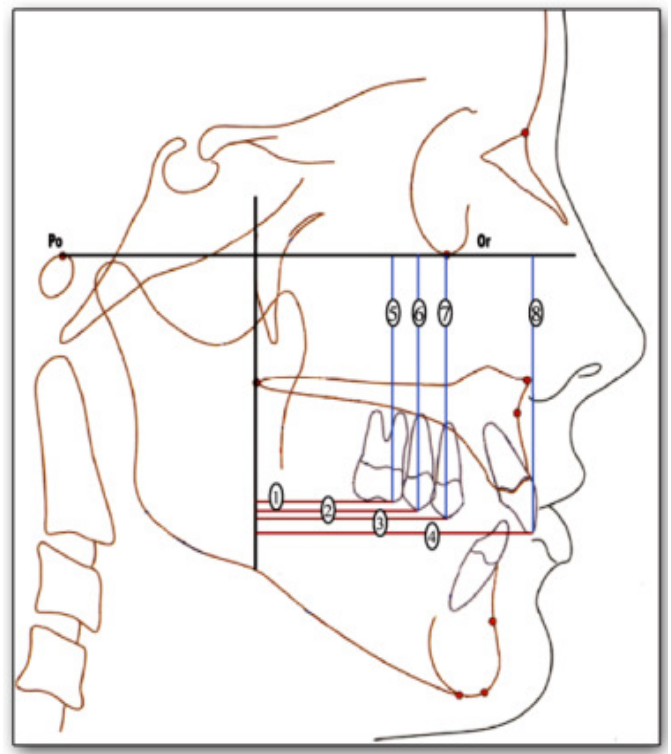

Fig (6) Dental linear measurements; 1:U6-PTV, 2: U5-PTV, 3: U4-PTV, 3: U1-PTV, 5: U6-FH, 6: U5-FH,7: U4-FH, 8: U1-FH.

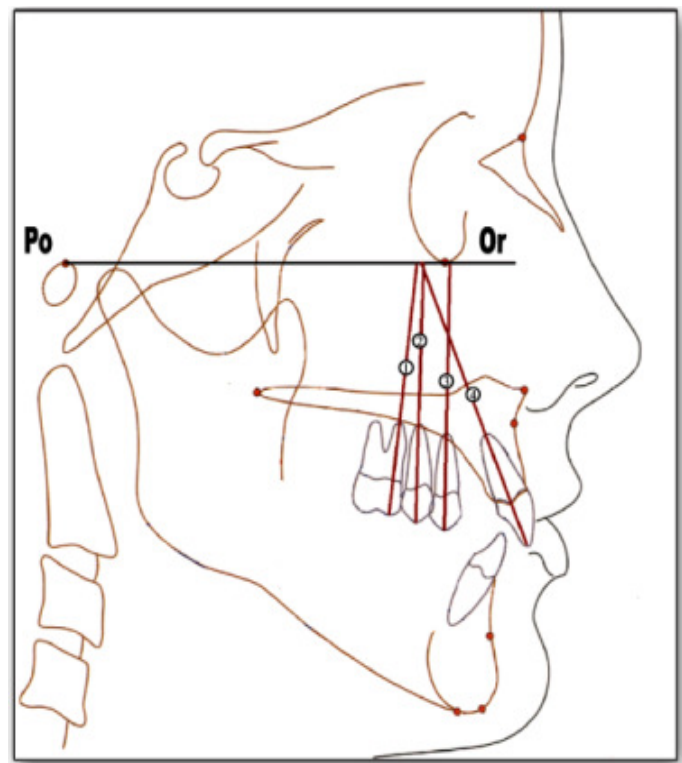

Fig (7) Dental angular measurements 1: U6-FH, 2: U5-FH,3: U4-FH, 4: U1-FH. 
Egyptian

Orthodontic Journal

\section{- Dental linear measuremen}

1- U6- PTV: Distance of a perpendicular line from the mesiobuccal cusp tip of the maxillary right first molars to pterygoid vertical plane.

2- U5- PTV: Distance of a perpendicular line from the buccal cusp tip of the maxillary second premolar to pterygoid vertical plane.

3- U4- PTV: Distance of a perpendicular line from the buccal cusp tip of the maxillary first premolar to pterygoid vertical plane.

4- U1-PTV: Distance of a perpendicular line from the incisal tip of most prominent maxillary central incisor to pterygoid vertical plane.

5- U6- FH: Distance of a perpendicular line from the mesiobuccal cusp tips of the maxillary first molars to Frankfort horizontal plane.

6- U5- FH: Distance of a perpendicular line from the mesiobuccal cusp tips of the maxillary second premolars to Frankfort horizontal plane.

7- U4- FH: Distance of a perpendicular line from the mesiobuccal cusp tips of the maxillary first premolars to Frankfort horizontal plane.

8- U1- FH: Distance of a perpendicular line from the incisal tip of most prominent maxillary central incisor to Frankfort horizontal plane.

\section{- Dental angular measurements (Fig 7):}

1- U6- FH: Angle between long axis of the maxillary first molars and Frankfort horizontal plane.

2- U5- FH: Angle between long axis of the maxillary second premolars and Frankfort horizontal plane.

3- U4- FH: Angle between long axis of the maxillary first premolars and Frankfort horizontal plane.

4- U1- FH: Angle between long axis of the maxillary central incisors and Frankfort horizontal plane. 


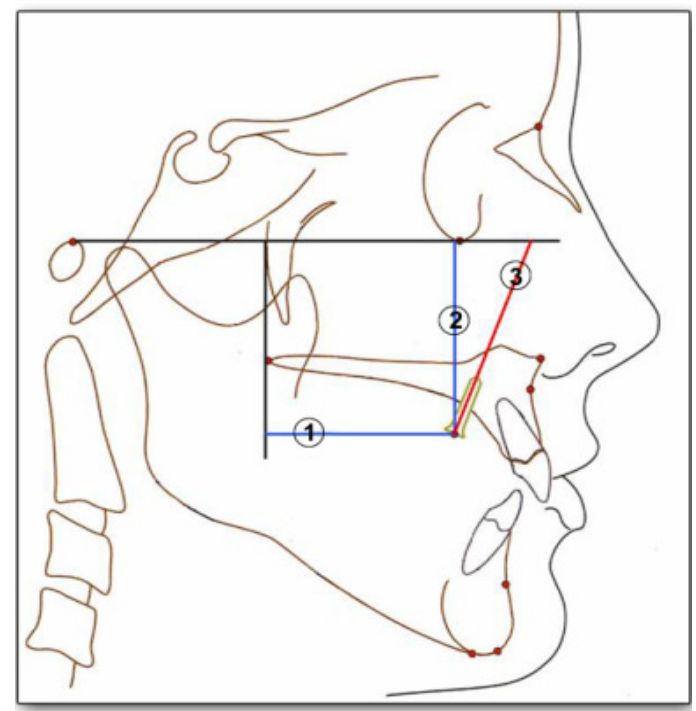

Fig (8) linear and angular measurements of titanium screw, 1: TS-PTV, 2: TS-FH, 3: TS (axis)-FH.

\section{- Linear and angular measurements of the titanium screw (Fig 8):}

1- TS- PTV: Distance of a perpendicular line from the centre of the head of the titanium screw to pterygoid vertical plane.

2- TS- FH: Distance of a perpendicular line from the centre of the head of the titanium screw to Frankfort horizontal plane.

3- TS (axis)- FH: Angle between long axis of the titanium screw and Frankfort horizontal plane.

\section{Statistical analysis}

All data and measurements presented in this study were subjected to statistical evaluation using the mean \pm standard deviation (t-test), by SPSS V (16). $\mathrm{P} \leq 0.05$ is considered statistically significant, where $\mathrm{P} \leq 0.001$ is considered statistically highly significant.

\section{RESULTS}

This study was carried out on 30 patients. The patients were divided into two equal groups, group I treated by PA, and group II treated by BAPA. 
Clinically successful distalization (super Class I molar relationship) was achieved in both groups. In the BAPA group, all of the intraosseous screws remained stable during the distalization period. However, a slight mobility of one screw was observed during removal of the appliance. After removing the acrylic plate, mild to moderate soft tissue irritation was detected on the palatal mucosa, but this was resolved in a few days.

The means, standard deviations and the significance of the treatment changes of all measurements of group I (pendulum appliance group) are reported in tables from 1 to 7 .

\section{1) Pretreatment and postdistalization comparison of the PA (tables 1:5).}

Table (1): Changes in the dental cast measurements in PA group.

\begin{tabular}{|l|c|c|c|c|}
\hline Dental cast analysis & Pretreatment & Post-treatment & T test & P value \\
\hline $\begin{array}{l}\text { Maxillary arch } \\
\text { perimeter (mm) }\end{array}$ & $70.20 \pm 3.87$ & $81.90 \pm 3.94$ & 12.756 & $0.001^{* *}$ \\
\hline $\begin{array}{l}\text { Maxillary intercanine } \\
\text { width (mm) }\end{array}$ & $33.395 \pm 2.49$ & $34.33 \pm 2.44$ & 1.476 & 0.166 \\
\hline $\begin{array}{l}\text { Maxillary intermolar } \\
\text { width (mm) }\end{array}$ & $49.73 \pm 2.11$ & $52.50 \pm 2.49$ & 4.669 & $0.001^{* *}$ \\
\hline Overjet (mm) & $2.77 \pm 0.41$ & $3.99 \pm 0.45$ & 1.950 & $0.037^{*}$ \\
\hline Overbite (\%) & $44.78 \pm 6.20$ & $31.23 \pm 4.82$ & 5.214 & $0.001 * *$ \\
\hline
\end{tabular}

$* \mathrm{p} \leq 0.05$ (significant), $\quad * * \mathrm{p} \leq 0.001$ (Highly significant).

Table (2): Changes in the model occlusal photocopies measurement in PA group.

\begin{tabular}{|l|c|c|c|c|}
\hline $\begin{array}{c}\text { Model occlusal photocopies } \\
\text { analysis }\end{array}$ & Pretreatment & Post-treatment & T test & P value \\
\hline UL6 axis angle (degree) & $19.225 \pm 3.15$ & $24.84 \pm 5.52$ & 3.682 & $0.003^{*}$ \\
\hline UR6 axis angle (degree) & $22.304 \pm 4.77$ & $31.15 \pm 3.85$ & 3.722 & $0.003^{*}$ \\
\hline UL4 axis angle (degree) & $70.46 \pm 7.80$ & $70.30 \pm 13.39$ & 0.043 & 0.967 \\
\hline UR4 axis angle (degree) & $76.07 \pm 13.7$ & $74.61 \pm 12.9$ & 0.510 & 0.619 \\
\hline
\end{tabular}

$* \mathrm{p} \leq 0.05$ (significant). 
Table (3): Changes in the cephalometric skeletal measurements in PA group.

\begin{tabular}{|l|c|c|c|c|}
\hline Skeletal measurements & Pretreatment & Post-treatment & T test & P value \\
\hline SNA angle (degree) & $82.03 \pm 4.08$ & $82.69 \pm 4.44$ & 1.180 & 0.261 \\
\hline SNB angle (degree) & $78.11 \pm 5.29$ & $78.15 \pm 5.51$ & 0.150 & 0.883 \\
\hline ANB angle (degree) & $4.11 \pm 1.55$ & $4.46 \pm 1.80$ & 1.389 & 0.190 \\
\hline FMA angle (degree) & $27.731 \pm 4.42$ & $29 \pm 4.45$ & 0.688 & 0.104 \\
\hline $\begin{array}{l}\text { Total anterior facial } \\
\text { height (N -Me) (mm) }\end{array}$ & $116.5 \pm 7.37$ & $118.9 \pm 6.91$ & 3.658 & $0.023^{*}$ \\
\hline $\begin{array}{l}\text { Lower anterior facial } \\
\text { height (ANS-Me) (mm) }\end{array}$ & $65.57 \pm 4.18$ & $66.76 \pm 5.16$ & 3.247 & $0.042^{*}$ \\
\hline $\begin{array}{l}\text { Posterior facial height } \\
\text { (S-Go) (mm) }\end{array}$ & $76.94 \pm 6.82$ & $77 \pm 6.22$ & 0.072 & 0.944 \\
\hline
\end{tabular}

$* \mathrm{p} \leq 0.05$ (significant).

Table (4) Changes in the cephalometric dental linear measurements in PA group.

\begin{tabular}{|l|c|c|c|c|}
\hline $\begin{array}{c}\text { Dental linear } \\
\text { measurements }\end{array}$ & Pretreatment & Post-treatment & T test & P value \\
\hline U6- PTV $(\mathrm{mm})$ & $26.38+2.15$ & $20.19 \pm 2.81$ & 11.132 & $0.001^{* *}$ \\
\hline U5- PTV $(\mathrm{mm})$ & $32.60+2.63$ & $30.60+4.65$ & 1.471 & 0.165 \\
\hline U4- PTV $(\mathrm{mm})$ & $40.23 \pm 3.02$ & $42.87 \pm 3.99$ & 2.639 & $0.048^{*}$ \\
\hline U1- PTV $(\mathrm{mm})$ & $55.11_{\underline{4}}+4.71$ & $56.39 \pm 4.56$ & 3.665 & $0.003^{*}$ \\
\hline U6- FH $(\mathrm{mm})$ & $46.80 \pm 3.30$ & $46.46 \pm 2.91$ & 0.666 & 0.518 \\
\hline U5- FH $(\mathrm{mm})$ & $48.08 \pm 2.09$ & $48.57 \pm 3.40$ & 1.035 & 0.321 \\
\hline U4- FH $(\mathrm{mm})$ & $49.46 \pm 3.05$ & $49.80 \pm 3.04$ & 0.719 & 0.486 \\
\hline U1- FH $(\mathrm{mm})$ & $54.73 \pm 3.93$ & $54.69 \pm 3.35$ & 0.066 & 0.949 \\
\hline
\end{tabular}

${ }^{*} \mathrm{p} \leq 0.05$ (significant), ${ }^{* *} \mathrm{p} \leq 0.001$ (Highly significant).

Table (5): Changes in the cephalometric dental angular measurements in PA group.

\begin{tabular}{|l|c|c|c|c|}
\hline $\begin{array}{c}\text { Dental angular } \\
\text { measurements }\end{array}$ & Pretreatment & Post-treatment & T test & P value \\
\hline U6- FH (degree) & $75.76 \pm 6.12$ & $66.92 \pm 8.25$ & 7.373 & $0.001^{* *}$ \\
\hline U5- FH (degree) & $83.75+2.98$ & $81.75+7.48$ & 1.078 & 0.301 \\
\hline U4- FH (degree) & $89.96 \pm 7.887$ & $93.84 \pm 9.654$ & 3.889 & $0.028^{*}$ \\
\hline U1- FH (degree) & $104.10 \pm 9.654$ & $106.90 \pm 10.07$ & 1.963 & $0.049^{*}$ \\
\hline
\end{tabular}

${ }^{*} \mathrm{p} \leq 0.05$ (significant), ${ }^{* *} \mathrm{p} \leq 0.001$ (Highly significant). 


\section{2) Pretreatment and postdistalization comparison of BAPA are shown in} tables $(6: 10)$.

Table (6): Changes in the dental cast measurements.

\begin{tabular}{|l|c|c|c|c|}
\hline \multicolumn{1}{|c|}{ Dental cast analysis } & Pretreatment & Post-treatment & T test & P value \\
\hline $\begin{array}{l}\text { Maxillary arch } \\
\text { perimeter }(\mathrm{mm})\end{array}$ & $72.71 \pm 5.33$ & $81.71 \pm 4.28$ & 9.317 & $0.001^{* *}$ \\
\hline $\begin{array}{l}\text { Maxillary intercanine } \\
\text { width }(\mathrm{mm})\end{array}$ & $33.832 \pm 2.47$ & $34.79 \pm 2.60$ & 2.865 & $0.015^{*}$ \\
\hline $\begin{array}{l}\text { Maxillary intermolar } \\
\text { width }(\mathrm{mm})\end{array}$ & $49.20 \pm 2.10$ & $51.34 \pm 2.51$ & 7.369 & $0.001^{* *}$ \\
\hline Overjet (mm) & $2.81 \pm 1.13$ & $2.55 \pm 1.08$ & 1.142 & 0.324 \\
\hline Overbite (\%) & $43.51 \pm 4.72$ & $34.50 \pm 4.93$ & 2.277 & $0.044^{*}$ \\
\hline
\end{tabular}

${ }^{*} \mathrm{p} \leq 0.05$ (significant), ${ }^{* *} \mathrm{p} \leq 0.001$ (Highly significant).

Table (7): Changes in the model occlusal photocopies measurements in BAPA group.

\begin{tabular}{|l|c|c|c|c|}
\hline Model occlusal photocopies & Pretreatment & Post-treatment & T test & P value \\
\hline UL6 axis angle (degree) & $20.66 \pm 3.39$ & $26.08 \pm 2.81$ & 5.100 & $0.001^{* *}$ \\
\hline UR6 axis angle(degree) & $22.66 \pm+3.79$ & $30.83 \pm 12.48$ & 2.444 & $0.033^{*}$ \\
\hline UL4 axis angle (degree) & $71.83 \pm 20.79$ & $73.33 \pm 18.77$ & 0.121 & 0.906 \\
\hline UR4 axis angle (degree) & $67.33 \pm 12.58$ & $71.08 \pm 10.79$ & 1.356 & 0.202 \\
\hline
\end{tabular}

${ }^{*} \mathrm{p} \leq 0.05$ (significant), ${ }^{* *} \mathrm{p} \leq 0.001$ (Highly significant).

Table (8): Changes in the cephalometric skeletal measurements in BAPA group.

\begin{tabular}{|l|c|c|c|c|}
\hline Skeletal measurements & Pretreatment & Post-treatment & T test & P value \\
\hline SNA angle (degree) & $81.66 \pm 4.81$ & $81.87 \pm 4.32$ & 0.635 & 0.539 \\
\hline SNB angle (degree) & $77.54 \pm 4.42$ & $77.33 \pm 3.92$ & 0.714 & 0.490 \\
\hline ANB angle (degree) & $4.12 \pm 1.35$ & $4.62 \pm 1.33$ & 2.253 & 0.086 \\
\hline FMA angle (degree) & $30.619 \pm 4.96$ & $32.16 \pm 4.21$ & 0.287 & 0.780 \\
\hline $\begin{array}{l}\text { Total anterior facial } \\
\text { height (N-Me) (mm) }\end{array}$ & $112.175 \pm 7.03$ & $113.8 \pm 5.94$ & 1.789 & $0.041^{*}$ \\
\hline $\begin{array}{l}\text { Lower anterior facial } \\
\text { height (ANS-Me) (mm) }\end{array}$ & $66.16 \pm 4.44$ & $67.25 \pm 4.29$ & 2.519 & $0.029^{*}$ \\
\hline $\begin{array}{l}\text { Posterior facial height } \\
\text { (S-Go) (mm) }\end{array}$ & $68.62 \pm 7.51$ & $69.29 \pm 6.70$ & 1.201 & 0.255 \\
\hline
\end{tabular}

$* p \leq 0.05$ (significant). 
Table (9): Changes in the cephalometric dental linear measurements in BAPA group.

\begin{tabular}{|l|c|c|c|c|}
\hline $\begin{array}{c}\text { Dental linear } \\
\text { measurements }\end{array}$ & Pretreatment & Post-treatment & T test & P value \\
\hline U6- PTV $(\mathrm{mm})$ & $24.58 \pm 4.01$ & $19.45 \pm 4.32$ & 8.535 & $0.001^{* *}$ \\
\hline U5- PTV $(\mathrm{mm})$ & $31.11 \pm 4.71$ & $27.91 \pm 3.74$ & 4.168 & $0.002^{*}$ \\
\hline U4- PTV $(\mathrm{mm})$ & $37.08 \pm 4.12$ & $35.20 \pm 3.652$ & 1.828 & $0.041^{*}$ \\
\hline U1- PTV $(\mathrm{mm})$ & $52.58 \pm 4.44$ & $52.10 \pm 3.88$ & 0.779 & 0.453 \\
\hline U6- FH $(\mathrm{mm})$ & $44.75 \pm 5.12$ & $44.12 \pm 4.61$ & 1.238 & 0.241 \\
\hline U5- FH $(\mathrm{mm})$ & $46 \pm 4.69$ & $46.87 \pm 4.85$ & 1.722 & 0.113 \\
\hline U4- FH $(\mathrm{mm})$ & $47.20 \pm 4.71$ & $47.62 \pm 4.88$ & 2.186 & 0.051 \\
\hline U1- FH $(\mathrm{mm})$ & $52.04 \pm 5.73$ & $52.37 \pm 5.88$ & 0.500 & 0.627 \\
\hline
\end{tabular}

${ }^{*} \mathrm{p} \leq 0.05$ (significant), ${ }^{* *} \mathrm{p} \leq 0.001$ (Highly significant).

Table (10): Changes in the cephalometric dental angular measurements in BAPA group.

\begin{tabular}{|l|l|l|l|l|}
\hline $\begin{array}{c}\text { Dental angular } \\
\text { measurements }\end{array}$ & Pretreatment & Post-treatment & \multicolumn{1}{|c|}{ T test } & P value \\
\hline U6- FH (degree) & $78.87 \pm 6.65$ & $71.25 \pm 5.12$ & 5.807 & $0.001^{* *}$ \\
\hline U5- FH (degree) & $83.03 \pm 4.58$ & $79.635 \pm 3.212$ & 2.556 & $0.043^{*}$ \\
\hline U4- FH (degree) & $88.33 \pm 2.72$ & $85.964 \pm 2.74$ & 2.471 & $0.039^{*}$ \\
\hline U1- FH (degree) & $104.16 \pm 6.24$ & $102.95 \pm 5.81$ & 3.657 & $0.038^{*}$ \\
\hline
\end{tabular}

$* \mathrm{p} \leq 0.05$ (significant), ${ }^{* *} \mathrm{p} \leq 0.001$ (Highly significant).

3) Comparison of the mean changes between the PA group(I) and PABA group (II) are illustrated in tables (11-13).

Table (11): Comparison of the dental cast mean changes between group I and II.

\begin{tabular}{|l|c|c|c|c|}
\hline \multicolumn{1}{|c|}{ Dental cast analysis } & GI & GII & T test & P value \\
\hline $\begin{array}{l}\text { Maxillary arch } \\
\text { perimeter }(\mathrm{mm})\end{array}$ & $11.70 \pm 0.070$ & $9 \pm 1.50$ & 2.332 & $0.014^{*}$ \\
\hline $\begin{array}{l}\text { Maxillary intercanine } \\
\text { width (mm) }\end{array}$ & $0.935 \pm 0.273$ & $0.958 \pm 0.152$ & 0.062 & 0.951 \\
\hline $\begin{array}{l}\text { Maxillary intermolar } \\
\text { width (mm) }\end{array}$ & $2.769 \pm 0.591$ & $2.141 \pm 0.290$ & 0.925 & 0.364 \\
\hline Overjet (mm) & $1.22 \pm 0.37$ & $-0.26 \pm 0.051$ & 3.542 & $0.008^{*}$ \\
\hline Overbite (\%) & $-13.55 \pm 1.38$ & $-9.01 \pm 2.21$ & 1.758 & 0.055 \\
\hline
\end{tabular}

$* p \leq 0.05$ (significant). 
Egyptian

Orthodontic Journal

Table (12):Comparison of the model occlusal photocopies mean changes between groupI\&II.

\begin{tabular}{|c|c|c|c|c|}
\hline $\begin{array}{c}\text { Model occlusal } \\
\text { photocopies }\end{array}$ & GI & GII & T test & P value \\
\hline UL6 axis angle (degree) & $5.615_{ \pm}+1.434$ & $5.42 \pm 0.782$ & 0.180 & 0.596 \\
\hline UR6 axis angle (degree) & $8.846 \pm 2.286$ & $8.17 \pm 2.955$ & 0.22 & 0.827 \\
\hline UL4 axis angle (degree) & $-0.16 \pm 0.963$ & $1.5 \pm 1.314$ & 2.412 & $0.048^{*}$ \\
\hline UR4 axis angle (degree) & $-1.46 \pm 1.325$ & $3.75 \pm 0.635$ & 2.628 & $0.044^{*}$ \\
\hline
\end{tabular}

$* \mathrm{p} \leq 0.05$ (significant).

Table (13): Comparison of the cephalometric skeletal mean changes between group I\& II.

\begin{tabular}{|l|c|c|c|c|}
\hline \multicolumn{1}{|c|}{ Skeletal measurements } & GI & GII & T test & P value \\
\hline SNA angle (degree) & $0.66 \pm 0.677$ & $0.21 \pm 0.205$ & 0.450 & 0.657 \\
\hline SNB angle (degree) & $0.04 \pm 0.173$ & $-0.21 \pm 0.178$ & 0.553 & 0.586 \\
\hline ANB angle (degree) & $0.35 \pm 0.166$ & $0.5 \pm 0.202$ & 0.566 & 0.577 \\
\hline FMA angle (degree) & $1.269 \pm 0.508$ & $1.541 \pm 0.562$ & 0.360 & 0.722 \\
\hline $\begin{array}{l}\text { Total anterior facial } \\
\text { height (N-Me) (mm) }\end{array}$ & $2.4 \pm 0.460$ & $1.625 \pm 0.262$ & 0.708 & 0.486 \\
\hline $\begin{array}{l}\text { Lower anterior facial } \\
\text { height (ANS-Me) (mm) }\end{array}$ & $1.19 \pm 0.98$ & $1.09 \pm 0.330$ & 0.621 & 0.541 \\
\hline $\begin{array}{l}\text { Posterior facial height } \\
\text { (S-Go) (mm) }\end{array}$ & $0.06 \pm 0.506$ & $0.67 \pm 0.347$ & 0.508 & 0.617 \\
\hline
\end{tabular}

Table (14): Comparison of the cephalometric dental linear mean changes between group I\& II.

\begin{tabular}{|l|c|c|c|c|}
\hline Dental linear measurements & GI & GII & T test & P value \\
\hline U6- PTV $(\mathrm{mm})$ & $-6.192 \pm 2.005$ & $-5.13 \pm 2.079$ & 1.306 & 0.204 \\
\hline U5- PTV $(\mathrm{mm})$ & $-2.141 \pm 1.301$ & $-3.20 \pm 0.852$ & 2.551 & 0.077 \\
\hline U4- PTV $(\mathrm{mm})$ & $2.64 \pm 0.97$ & $-1.88 \pm 0.471$ & 2.658 & $0.017^{*}$ \\
\hline U1- PTV $(\mathrm{mm})$ & $1.28 \pm 0.15$ & $-0.48 \pm 0.560$ & 2.325 & $0.024^{*}$ \\
\hline U6- FH $(\mathrm{mm})$ & $-0.34 \pm 0.975$ & $-0.63 \pm 0.310$ & 0.289 & 0.775 \\
\hline U5- FH $(\mathrm{mm})$ & $0.49 \pm 0.325$ & $0.87 \pm 0.421$ & 0.499 & 0.623 \\
\hline U4- FH $(\mathrm{mm})$ & $0.34 \pm 0.270$ & $0.42 \pm 0.517$ & 0.864 & 0.397 \\
\hline U1- FH $(\mathrm{mm})$ & $-0.04 \pm 0.366$ & $0.33 \pm 0.385$ & 0.482 & 0.634 \\
\hline
\end{tabular}

$* \mathrm{p} \leq 0.05$ (significant). 
Egyptian

Orthodontic Journal

Table (15) Comparison of the cephalometric dental angular mean changes between groupI\&II.

\begin{tabular}{|l|c|c|c|c|}
\hline Dental angular measurements & GI & GII & T test & P value \\
\hline U6- FH (degree) & $-8.841 \pm 1.60$ & $-7.62 \pm 1.313$ & 2.014 & 0.056 \\
\hline U5- FH (degree) & $-1.875+0.930$ & $-3.395 \pm 1.368$ & 2.455 & 0.062 \\
\hline U4- FH (degree) & $3.88 \pm 1.767$ & $-2.37 \pm 0.020$ & 2.996 & $0.032 *$ \\
\hline U1- FH (degree) & $2.80 \pm 0.420$ & $-1.210 \pm 0.430$ & 2.967 & $0.041^{*}$ \\
\hline
\end{tabular}

$* \mathrm{p} \leq 0.05$ (significant).

Table (16): Cephalometric linear and angular measurements of the titanium screw (TS) before and after distalization period in BAPA group.

\begin{tabular}{|l|c|c|c|c|}
\hline $\begin{array}{c}\text { Titanium screw } \\
\text { measurements }\end{array}$ & Pretreatment & Post-treatment & T test & P value \\
\hline TS- PTV (mm) & $37.53 \pm 4.12$ & $38.64 \pm 4.07$ & 0.890 & 0.408 \\
\hline TS- FH (mm) & $37.03 \pm 2.65$ & $36.91 \pm 3.90$ & 0.074 & 0.943 \\
\hline TS (axis)- FH (degree) & $71.57 \pm 7.74$ & $72.28 \pm 8.09$ & 0.454 & 0.666 \\
\hline
\end{tabular}

Table (17): Comparison of the distalization time (in month) between group I and II.

\begin{tabular}{|l|c|c|c|c|}
\hline & GI & GII & T test & P value \\
\hline Time of distalization & $5.65 \pm 0.96$ & $6.49 \pm 0.86$ & 2.433 & $0.043 *$ \\
\hline
\end{tabular}

$* \mathrm{p} \leq 0.05$ (significant).

\section{DISCUSSION}

The treatment of Class II malocclusions has always been a subject of great interest for orthodontists. Various strategies have been used including extraction of teeth, extraoral forces, interarch elastics, functional appliances, interarch noncompliance techniques, and more recently, intra-arch maxillary molar distalizing techniques. Distal movement of the maxillary first molar is a common goal in the treatment of a Class II molar relationship. 
The non compliant BAPA and PA were the appliances of choice to be used in the current study. The purpose of this study was to evaluate the dentofacial changes after distalization of maxillary first molars using BAPA in the treatment of dental Class II cases with a mildly crowded permanent dentition and compare the data with those of similar group of patients treated with PA.

The PA consisted schematically of an anchorage unit and an active unit. The anchorage was maintained with a modified Nance appliance, which employed the upper first premolars. Some authors used second premolars beside the first premolars to gain even more anchorage against the mesially directed forces ${ }^{(12,26)}$. In this study first premolars were used only to encourage distal drift of the second premolars along with the first molars in the course of treatment with the help of the transeptal fibers.

In the present study, two titanium intraosseous screws $(2.0 \mathrm{~mm}$ diameter and $9 \mathrm{~mm}$ length) were used as rigid bone anchors in BAPA design. The desired immobility of these screws relies on a mechanical locking between the screw and the surrounding bone ${ }^{(33,54,55)}$.

Kircelli et al., ${ }^{(36)}$ stated that the elimination of the osseointegration period (2- 6 months), wider range of application sites, simple procedures during the insertion and removal processes and lower cost make intraosseous screws the preferable as rigid bone anchors. The paramedian region could be the site of choice for miniscrew placement, and the optimal areas are those at $3 \mathrm{~mm}$ from the median suture and $7 \mathrm{~mm}$ from the incisive foramen ${ }^{(56)}$. In the current study, the bilateral screws were applied in the paramedian region of the palate in all patients to withstand reciprocal forces during the distalization period.

Only one patient in the current study had slight mobility of one of the intraosseous screws. The lower failure rate here was probably due to the use of 2 screws in all patients and the acrylic plate that distributed the counteracting forces to both the screw and the palate. Similar opinion was reported by Ozsoy et al ${ }^{(57)}$.

The cephalometric analysis of the present study showed insignificant forward displacement by $1.1 \mathrm{~mm}$ in the screws. This finding was supported by Oncag et al., ${ }^{(58)}$ who had $0.8 \mathrm{~mm}$ forward movement in the implant. 
Egyptian

Orthodontic Journal

In the current study, the force applied for molar distalization was $300 \mathrm{gm}$ for each side as recommended by Bondemark et al ${ }^{(59)}$.

Maxillary molar distalization continued till achieving super Class I molar relation. This overcorrection is necessary and routinely prepared anchorage for all distalization treatment, because molar anchorage loss will invariably occur during retraction of the premolars, canines, and incisors ${ }^{(60,61)}$.

In the present study, detaching the acrylic plate from the screws head when removing the appliance was done without any difficulty unlike previous studies which used $\mathrm{BAPA}^{(36,57)}$; this may be due to the use of chemical curing, composite resin instead of self cure acrylic resin to attach the acrylic plate to the screws head.

A super Class I molar relationship was achieved in 6.5 months in the BAPA group and in 5.65 months in the PA group. The main reason for this difference was thought to be the molar movement needed before treatment. The duration of distalization in the BAPA group was similar to the results of Önçag et al $^{(58)}$ who used an osseointegrated implant supported pendulum, and Kircelli et al., ${ }^{(36)}$ and Ozsoy et al., ${ }^{(57)}$ who used bone anchorage pendulum appliance; however, Escobar et al ${ }^{(62)}$ reported longer distalization periods (7.8 months) with a bone-supported pendulum. The distalization time in PA group was matched with previous authors $^{(12,24,26,64-66)}$, yet longer than others ${ }^{(3,67)}$.

There was a significant increase in the maxillary arch perimeter in both groups, $11.7 \mathrm{~mm}$ in PA group and $9 \mathrm{~mm}$ in BAPA group. These finding could be explained by the significant distal movement of the maxillary molars. These results in PA group were compatible with previous studies $(26,24,63,65,68)$, while the result in BAPA were compatible with those of Kircelli et al, ${ }^{(36)}$ and Escobar et $\mathrm{al}^{(62)}$. The difference between the two groups was significant. This may be due to anchorage loss in the anterior segment in the PA group.

The maxillary intermolar width was significantly increased in both groups, which was slightly greater in PA group. The increase in the intermolar width was related to the distalization of the first molar through the wide area of the dental arch. The result in PA group was in agreement 
with those of other studies ${ }^{(3,68,69)}$ while the result in BAPA were in agreement with those of Kircelli et $\mathrm{al}^{(36)}$ and Escobar et $\mathrm{al}^{(62)}$.

The upper intercanine widths showed a non significant change in PA group. This was agreed with Hilgers ${ }^{(12)}$ and others ${ }^{(11,24,26,63-66,69)}$. The upper intercanine widths showed a significant increase in BAPA group. This increase may be attributed to distal movement of the maxillary anterior teeth in BAPA group into a wide area of the dental arch.

The results of the present study revealed that, there was no effect on the sagittal position of the maxilla and the mandible in the two groups. There was a non significant increase in the SNA angle. This observation may suggest that, A-point was not affected by anteriorly oriented forces within a relatively short period of time. These skeletal findings confirming the previous findings ${ }^{(26,36,63,64,70,71)}$. However, other authors reported different and controversy finding. Keles and Sayinsu ${ }^{(20)}$ found significant increase in SNA angle. They blamed this increase to the proclination of the incisors. Angelieri et al. ${ }^{(72)}$ reported significant backward movement of point $\mathrm{A}$ by $1.1^{\circ}$ and attributed this reduction in the SNA angle during distalization to the significant lingual tipping of the maxillary incisors, which yielded posterior displacement of A- point.

Very little increase was occurred in the mandibular plane angle in both groups at the end of distalization, where as the overbite was decreased significantly in the two groups but these changes showed no significant difference between the groups. The first molars were intruded insignificantly; in contrast, the first and second premolars were extruded insignificantly. The extrusion of the premolars in PA group is explained by the fact that the Nance button is supported by the premolars, and activation of the appliance produces a vertical force component that leads to extrusion of the premolars and intrusion of the molars. As mentioned previously, the vertical changes led to a reduction in overbite, consequent to the effect of the extrusion of the premolars, which could have acted as a selective bite plate, allowing vertical development of the molars, associated with the clockwise mandibular rotation. So, these results suggest that the appliance is contraindicated in patient with excessive lower facial height and/or minimal overbite ${ }^{(3)}$. This outcome was homogenous with the significant distalization of the maxillary molars or 
changes in the facial vertical dimensions found in the present study. In addition, this was in agreement with previous studies $(24,26,36,57,58)$.

Also there was a significant increase in the lower anterior facial height (ANS- Me) and total anterior facial height (N- Me). This was similar to the increase reported by several authors ${ }^{(3,36,57,70)}$. However, the difference between the two groups was not significant. These significant changes in the facial vertical dimension could be explained by pushing of the upper molars distally in a narrower intermaxillary space act as a wedging action.

There was a significant increase of maxillary right and left first molar axis angle in both groups, this may attributed to distalization of the first molar through the wide area of the dental arch. However, there was no significant difference of maxillary right or left first molar axis angle changes between the two groups. In contrast, there was a significant difference of maxillary right and left first premolar axis angle changes between the two groups. These finding was explained by, distal tipping of the first premolar in BAPA group and mesial tipping of the first premolar in PA group.

In BAPA group, the maxillary molars moved distally a mean of 5.1 $\mathrm{mm}$ and the second and first premolars drifted distally a mean of 3.2 and $1.8 \mathrm{~mm}$, respectively as maxillary premolars was not used as anchorage units, and there was a slight decrease in the overjet with distal tipping of the maxillary central incisors.

These results supported by previous authors ${ }^{(36,57,58,62)}$. On the other hand, in PA group, there was mesial movement of the first premolars with a mean of 2.6 while there was distal movement of the first molars and second premolars with a mean of 6.19 and $2.1 \mathrm{~mm}$, respectively. The second premolars in PA group were free from any attachment, and they drifted distally via transeptal fibers during the distalization period. These findings were similar to those of previous reports ${ }^{(3,24,71,73)}$. In the present study, in BAPA group for every $1 \mathrm{~mm}$ of distal molar movement, there was $0.36 \mathrm{~mm}$ distal movement of the first premolar. On the other hand, in PA group for every $1 \mathrm{~mm}$ of distal molar movement, there was $0.43 \mathrm{~mm}$ mesial movement of the first premolar. 
Because reactive forces arising from the pendulum springs in BAPA were directly resisted by an intraosseous screw, the premolars were free from any attachment, and they drifted distally via transeptal fibers during the distalization period. As a result, a Class I relationship was simultaneously achieved in the second premolars in both groups and also in the first premolars in BAPA group. In the PA group, these amounts of anchorage loss can only be corrected by using the first molars as the anchorage unit in the second phase of the treatment. Maintaining the amount of molar distalization obtained in the first stage until the end of the second stage is difficult, and some clinicians even recommend extraoral appliances for this purpose. All the time spent to prevent relapse of the molars and to correct the anchorage loss of the premolar and anterior segments increased the total treatment time.

The maxillary incisors were retroclined by $1.2^{\circ}$ and distalized by $0.48 \mathrm{~mm}$ in the BAPA group and proclined by $2.8^{\circ}$ and $1.2 \mathrm{~mm}$ in the PA group. This is in accordance with Önçag et al ${ }^{(58)}$ Escobar et al ${ }^{(62)}$ and who found distal incisor movement in their implant-supported pendulum appliance groups. This amount of incisor retroclination was seen in BAPA group, probably due to the distal movement of the first and second premolars. This movement was favorable and will contribute favorably to treatment time.

Regarding the anterior anchorage loss in PA group, this finding was in agreement with that reported in other invistigations $(24,26,63,64,70,71)$. Also, this effect of the PA was matched with those of authors who used other different distalizing appliances ${ }^{(10,11,18)}$.

The average amounts of molar distal movement and tipping were $\left(5.12 \mathrm{~mm}, 7.6^{\circ}\right)$ in the BAPA group and $\left(6.19 \mathrm{~mm}, 8.8^{\circ}\right)$ in the PA group. The result showed that, the molar tipped $1.48^{\circ}$ per millimeter of distal tooth movement in BAPA group, and $1.42^{\circ}$ per millimeter in PA group. In other words, the two appliances were equally likely to tip the maxillary molars. These distal tipping and movements of the maxillary first molars were also found in other $\mathrm{BAPA}^{(36,59,60)}$ as Kircelli et al. ${ }^{(36)}\left(6.4 \mathrm{~mm}, 10.9^{\circ}\right)$, Ozsoy et al., ${ }^{(57)}\left(4.8 \mathrm{~mm}, 9.1^{\circ}\right)$, and Önçag et al., ${ }^{(58)}\left(5.1 \mathrm{~mm}, 7.06^{\circ}\right)$. Molar distalization and tipping in the PA group was found in Bussick and McNamara $^{(3)}\left(5.7 \mathrm{~mm}, 10.6^{\circ}\right)$, Byloff and Darendeliler ${ }^{(24)}\left(3.39 \mathrm{~mm}, 14.5^{\circ}\right)$, 
Egyptian

Orthodontic Journal

Taner et $\mathrm{al}^{(71)}\left(3.81 \mathrm{~mm}, 11.77^{\circ}\right)$, Ghosh and Nanda ${ }^{(73)}\left(3.37 \mathrm{~mm}, 8.36^{\circ}\right)$, Chiu et $\mathrm{al}^{(74)}\left(6.1 \mathrm{~mm}, 10.7^{\circ}\right)$ and Fuziy et $\mathrm{al}^{(66)}\left(4.6 \mathrm{~mm}, 18.5^{\circ}\right)$. The differences in distal tipping can be attributed to the differences in the amount of distalization needed and the duration of molar movement between the groups and might have been due to absence of erupted maxillary second molar in their samples. However, the amount of distal tipping in the PA group was not as high as in other studies in the results of Ozsoy et al. ${ }^{(59)}\left(2.7 \mathrm{~mm}, 5.3^{\circ}\right)$ and this was attributed to the slow rate of molar movement and the incorporation of uprighting bends when needed.

The maxillary second molars were fully erupted at the beginning of the treatment in the two studied groups. Kinzinger et al., ${ }^{(68)}$ reported that, with pendulum treatment, distal tipping of the first molars was less in patients with erupted second molars than in those whose second molars were not yet erupted. If a second molar has not erupted, it acts as a fulcrum and causes first molar tipping. Other studies ${ }^{(3,24,73,75)}$ concluded that second molars do not affect linear and angular changes in molar distalization. In the present study, the second molars were erupted, and tipping was noted in every subject.

One of the most characteristic aspects of BAPA is the simultaneous distal movement of premolars with molars. Moreover, anterior crowding has been spontaneously solved out because of the stretched transeptal fibers, consequently, the total treatment time is shortened.

\section{CONCLUSION}

On the basis of the results obtained from the present study, the following treatment effects were noted:

1. There was highly significant distal tipping of the maxillary first molar in both groups with no significant difference.

2. There was a significant mesial tipping of the maxillary first premolars and central incisors in PA group

3. Anchorage loss in the form of mesialization of maxillary first premolars and incisors was found in PA group; however BAPA group showed no anchorage loss. 
4. The changes in the maxillary first molar rotational axis angle were not significant between the two studied groups. However, there was a significant difference of maxillary first premolar rotational axis angle changes between the two groups.

5. The posterior facial height was not affected while there was an increased lower facial height, consequently the total facial height showed a larger dimension after distalization in the two studied groups.

6. The increase in the maxillary intermolar width was highly significant in both groups. This increase was similar between the two groups.

7. Highly significant increase in the maxillary arch perimeter was found in both groups, which was greater in PA group, indicating anchorage loss.

8. Insignificant differences in the sagital skeletal measurements (SNA, SNB and ANB angles) were found. Consequently, the effect of both appliances was mainly dentoalveolar in nature.

The BAPA appliance is an effective and minimally invasive, compliance free alternative for intraoral molar distalization without anchorage loss.

Further studies both after completion of the treatment and in the retention phase, are needed.

\section{REFERENCES}

1. Houston WJ, Stephens CD, Tulley WJ (1992): A text book of orthodontics (dental hand book) Class I malocclusion. Wrighter Oxford $2^{\text {nd }}$ ed. Chap. 10, 210.

2. Proffit WR, Fields HW, Sarver DM (2007): Contemporary orthodontics. $4^{\text {th }}$ ed. St Louis: Mosby.

3. Bussick TJ, McNamara JA (2000): Dentoalveolar and skeletal changes associated with the pendulum appliance. Am J Orthod Dentofacial Orthop. 117: 333- 43.

4. Runge ME, Martin JT, Bukai F (1999): Analysis of rapid maxillary molar distal movement without patient co-operation. Am J Orthod Dentofacial Orthop. 115: 153- 57. 
5. Herbst, E (1934): Dreissigjährige Erfahrungen mit dem RetentionsScharnier, Zahnärztl. Rundschau 43: 1515-1524, 1563-1568, 1611-1616. Quoted in Pancherz (1982): Class II correction in Herbst appliance treatment. Am J Orthod. 104- 113.

6. Jasper JJ (1987): The Jasper jumper- a fixed functional appliance. Sheboygan, Wis: American Orthodontics; 5- 27.

7. Klapper L (1999): The Superspring II: A new appliance for noncompliant Class II Patients. J. Clin. Orthod. 33: 50- 4.

8. Ucem T, Yukset S, Okay C, Gulsen A (2000): Effect of a three dimensional biometric maxillary Distalizing arch. Eur. J. Orthod. 22: $293-998$.

9. Rothenberg J, Campbell ES, Nanda R (2004): Class II correction with the Twin Force Bite Corrector. J Clin Orthod. 38: 232- 40.

10. Gianelly A, Vaitas AS, Thomas WM (1989): The use of magnets to move molars distally. Am J Orthod Dentofacial Orthop. 96: 161- 167.

11. Jones R, White M (1992): Rapid Class II molar correction with an open-coil jig. J. Clin. Orthod. 26: 661- 664.

12. Hilgers, JJ (1992): The Pendulum appliance for Class II non-compliance therapy. J. Clin. Orthod. 26: 706- 714.

13. Fraunhofer JA, Bonds PW, Johnson BE (1993): Force generation by orthodontic coil springs. Angle Orthod. 2: 145- 148.

14. Greenfield RL (1995): Fixed Piston appliance for rapid Class II correction. J. Clin. Orthod. 31: 174- 183.

15. Carano A, Testa M (1996): The Distal Jet for upper molar distalization. J.Clin. Orthod. 30: 374- 380.

16. Puente P (1997) : Class II correction with an edgewise-modified Nance appliance. J. Clin. Orthod. 31: 178- 182.

17. Giancotti, A, Cozza (1998): Nickel-titanium double loop system for simultaneous distalization of first and second molars. J. Clin. Orthod. 32: $255-260$. 
18. Fortini, A, Lupoli M, Parri M (1999): The first class appliance for rapid molar distalization. J. Clin. Orthod. 33: 322- 328.

19. Chung K, Park Y, Ko S (2000): C-space regainer for molar distalization. J .Clin .Orthod. 36: 32- 39.

20. Keles A, Sayinsu K (2000): A new approach in maxillary molar distalization: Intraoral bodily molar distalizer. Am J Orthod Dentofacial Orthop. 117: 39- 48.

21. Keles A (2001): Maxillary unilateral molar distalization with sliding mechanics: a preliminary investigation. Eur J Orthod. 23: 507- 515.

22. Mandurino, M, Balducci L (2001): Asymmetric distalization with a TMA transpalatal arch. J. Clin. Orthod. 35: 174- 178.

23. Scuzzo G, Pisani F, Takemoto K (1999): Maxillary molar distalization with a modified Pendulum appliance. J. Clin. Orthod. 33: 645 -50.

24. Byloff FK, Darendeliler MA (1997): Distal molar movement using the pendulum appliance. Part 1: Clinical and radiographic evaluation. Angle Orthod. 67: 249- 260.

25. Antonarakis GS \& Kiliaridis S (2008): Maxillary molar distalization with noncompliance intramaxillary appliance in class II malocclusion. Angle Orthod. 78: 1133- 1140.

26. Snodgrass DJ (1996): A fixed appliance for maxillary expansion, molar rotation, and molar distalization. J. Clin. Orthod. 30: 156- 159.

27. Toroglu MS, Uzel I, Cam OY, Hancioglu ZB (2001): Cephalometric evaluation of the effects of pendulum appliance on various vertical growth patterns and of the changes during short-term stabilization Clin. Orthod. Res. 4: 15- 27.

28. Joseph A, Butchart CJ (2000): An evaluation of the pendulum distalizing appliance. Semin Orthod. 6: 129- 135.

29. Roberts WE, Smith RK, Silberman Y, Mozsary PG, Smith RS (1984): Osseous adaptation to continuous loading of rigid endosseous implants .Am J Orthod. 86: 95- 111. 
30. Roberts WE, Marshall KJ, Mozsary P (1990): Rigid endosseous implant utilized as anchorage to protract molars and close atrophic extraction site. Angle Orthod. 60: 135- 52.

31. Roberts WE, Arbuckle GR, Analoui M (1996): Rate of mesial translation of mandibular molars using implant-anchored mechanics. Angle Orthod. 66: 331- 8.

32. Diedrich PR, Fuhrmann RA, Wehrbein H, Erpenstein H (1996): Distal movement of premolars to provide posterior abutments for missing molars. Am J Orthod Dentofacial Orthop. 109: 355- 60.

33. Wehrbein H, Feifel H, Diedrich P (1999) a : Palatal implant anchorage reinforcement of posterior teeth: a prospective study. Am J Orthod Dentofacial Orthop. 116: 678- 86.

34. Block MS, Hoffman DR (1995): A new device for absolute anchorage for orthodontics. Am J Orthod Dentofacial Orthop. 107: 251- 8.

35. Yamada K, Kuroda S, Deguchi T, Yamamoto T, YamashiroT (2009): Distal Movement of Maxillary Molars Using Miniscrew Anchorage in the Buccal Interradicular Region. Angle Orthod. 79: 78- 84.

36. Kircelli BH, Pektas ZO, Kircelli C (2006): Maxillary Molar Distalization with a Bone-Anchored Pendulum Appliance. Angle Orthod. 76; 4: 650- 659.

37. Creekmore TD, Eklund MK (1983): The possibility of skeletal anchorage. J .Clin .Orthod. 4: 266- 269.

38. Wehrbein H, Merz BR, Diedrich P $(1999)^{\mathrm{b}}$ : Palatal bone support for orthodontic implant anchorage- a clinical and radiological study. Eur J Orthod. 21: 65- 70.

39. Byloff FK, Karcher H, Clar E, Stoff F (2000): An implant to eliminate anchorage loss during molar distalization: A case report involving the Graz implant- supported pendulum. Inter. J. Adult Orthod. and Orthognathic Surgery. 15; (2) 129- 137.

40. Roberts WE, Nelson CL, Goodacre CJ (1994): Rigid implant anchorage to close a mandibular first molar extraction site. J Clin Orthod 28: 693- 704. 
41. Umemori M, Sugawara J, Mitani H, Nagasaka H, Kawamura H (1999): Skeletal anchorage system for open bite correction. Am J Orthod Dentofacial Orthop. 115: 166- 174.

42. Park HS, Bae SM, Kyung HM, Sung JH (2001): Micro-implant anchorage for treatment of skeletal Class I bialveolar protrusion. J Clin Orthod. 35: 417- 422.

43. Park HS, Kwon DG, Sung JH (2004): Nonextraction treatment with microscrew implant. Angle Orthod. 74: 539- 549.

44. Hansen K, pancherz H (1995): Long term effects of the Herbst appliance on the dental arches and arch relationships: A biometric study. Brit. J. Orthod. 22: 123- 134.

45. Adkins MD, Nanda RS, Currier GF (1990): Arch perimeter changes on rapid palatal expansion. Am J Orthod. 97: 194- 9.

46. Champagne M (1992): Reliability of measurements from photocopies of study models. J. Clin. Orthod. 26: 648- 50.

47. Downs WB (1956): Analysis of the dentofacial profile. Angle Orthod. 26: 191- 212.

48. Rakosi T (1982): An atlas and manual of cephalometric radiography. London, Wolf Medical Atlases pp 34- 65.

49. Athanasiou AE(1995):Orthodontic cephalometry. Mosby-Wolfe Atlases. 36- 39.

50. Steiner C (1960): The use of cephalometrics as an aid to planning and assessing orthodontic treatment. Am J Orthod. 46: 721- 735.

51. Rickettis RM (1981): Prespectivesen the clinical application of cephalometric. Angle Orthod. 51; 115- 150.

52. McNamara JA (1984): Dentofacial adaptation in adult patients following functional regulator therapy. Am J Orthod. 85: 57- 71.

53. Jacobson A (1985): Introduction to radiographic cephalometry. International Copyright Union. United States of America. 75- 81.

54. Smalley WM, Shapiro P, Hohl TH, Kokich VG, Branemark P (1988): Osseointegrated titanium implants for maxillofacial protraction in monkeys. Am J Orthod Dentofacial Orthop. 4: 285- 295. 
55. Majzoub Z, Finotti M, Miotti F, Giardino R, Aldini NN, Cordioli G (1999): Bone response to orthodontic loading of endosseous implants in the rabbit calvaria: early continuous distalizing forces. Eur J Orthod. 21: $223-230$.

56. Gracco A, Lombardo L, Cozzani M, Sicilianid G (2008): Quantitative cone-beam computed tomography evaluation of palatal bone thickness for orthodontic miniscrew placement. Am J Orthod Dentofacial Orthop. 134: 361- 9.

57. Ozsoy OP, Kırcelli PH, Özçırpıcı AA, Pektas ZO, Uçkand S (2008): Pendulum appliances with 2 anchorage designs: Conventional anchorage versus bone anchorage. Am J Orthod Dentofacial Orthop. 133: 339.e9- 339.e17.

58. Önçag $־$ G, Seçkin Ö, Dinçer B, Arikan F (2007): Osseointegrated implants with pendulum springs for maxillary molar distalization: a cephalometric study. Am J Orthod Dentofacial Orthop. 131: 16- 26.

59. Bondemark 1, Kurol J, Bernhold M (1994): Repelling magnets versus superelastic nickel-titanium coils in simultaneous distal movement of maxillary first and second molars. Angle Orthod. 64: 189- 198.

60. Dietz VS, Gianelly AA (2000): Molar distalization with the acrylic cervical occipital appliance. Semin Orthod. 6: 91- 97.

61. Haas AJ (2000): Headgear therapy: the most efficient way to distalize molars. Semin Orthod. 6: 79- 90.

62. Escobar SA, Tellez PA, Moncada CA, Villegas CA, Latorre CM, Obertid G (2007): Distalization of maxillary molars with the bone-supported pendulum: A clinical study. Am J Orthod Dentofacial Orthop. 131: 545- 9.

63. Eid H (1997): Evaluation of the pendulum appliance in gaining Class I molar relationship in class II malocclusion. M.S Thesis, Orthodontic Department, Cairo University.

64. Scuzzo G, Pisani F, Takemoto K (1999): Maxillary molar distalization with a modified Pendulum appliance. J. Clin. Orthod. 33: 645 -50.

65. El-Sayed HS (2003): A clinical evaluation of different intraoral maxillary molar distalizing techniques. M.S Thesis, Orthodontic Department, Cairo University. 
Egyptian

Orthodontic Journal

66. Fuziy A, Almeida M, Janson G, Angelieri F (2006): Sagittal, vertical, and transverse changes consequent to maxillary molar distalization with the pendulum appliance. Am J Orthod Dentofacial Orthop. 130: 502- 10 .

67. Hilgers JJ, Tracey S (2000): Hyperefficient orthodontic treatment. Clinical impression. Prolab Publication Ormco 9: 18- 26.

68. Kinzinger GM, Wehrbein H, Diedrich PR (2005) ${ }^{\mathrm{b}}$ : Molar distalization with a modified pendulum appliance- In Vitro analysis of the force systems and in Vivo study in children and adolescents. Angle Orthod. 75: 558- 567.

69. Abd El-Magid MT (2003): Evaluation of the Distal Jet and MultiDistalizing arch in distalization of maxillary molars. MD Thesis. Orthodontic Department, Mansoura University.

70. Chaques- Asensi J, Kalra V (2001): Effect of the pendulum appliance on the dentofacial complex. J. Clin. Orthod. 35: 254- 257.

71. Taner TU, Yukay F, Pehlivanoglu M, Çakırer B (2003): A comparative analysis of maxillary tooth movement produced by cervical headgear and pend-x appliance. Angle Orthod. 73: 686- 91.

72. Angelieri F, Almeida R, Almeida M, Fuziy A (2006): Dentoalveolar and skeletal changes associated with the pendulum appliance followed by fixed orthodontic treatment. Am J Orthod. Dentofacial Orthop. 129: 520- 7.

73. Ghosh J, Nanda RJ (1996): Evaluation of an intraoral maxillary molar distalization technique. Am J Orthod Dentofacial Orthop. 110: 639- 646.

74. Chiu PP, McNamara JA, FranchicL L (2005): A comparison of two intraoral molar distalization appliances: Distal jet versus pendulum. Am J Orthod Dentofacial Orthop. 128: 353- 65.

75. Joseph A, Butchart CJ (2000): An evaluation of the pendulum distalizing appliance. Semin Orthod. 6: 129- 135. 